\section{Questión}

Periodismo / Comunicación ISSN 1669-6581
- Av. $44 \mathrm{~N}^{\circ} 676,1^{\circ}$ piso

CP 1900 - La Plata - Argentina

www.perio.unlp.edu.ar/question

Educación y medios, en tiempos de pandemia: desafíos en escenarios inciertos

Gerardo Bianchetti

https://doi.org/10.24215/16696581e357

\title{
EDUCACIÓN y MEDIOS, en TIEMPOS de PANDEMIA: desafíos en escenarios inciertos
}

\section{EDUCATION and MEDIA, in TIMES of PANDEMIC: challenges in uncertain scenarios}

\begin{abstract}
Mgs. R. Gerardo Bianchetti Integrante del Instituto de Comunicación, Políticas y Sociedad (INCOPOS) UNSa Profesor Emérito de la UNSa. Ex Titular de Política Educacional. Prof. Invitado en Estado Poder y Medios. Fue investigador del CIUNSa categoría1 y Docente 20 años en Historia de la Educación Argentina por extensión de funciones. Realizó publicaciones en Argentina, Brasil y España. gerbian11@gmail.com
\end{abstract}

\section{Resumen}

La Pandemia estableció un nuevo punto de partida, ya que afecta el funcionamiento de la economía mundial, impide o dificulta la circulación de personas entre países y al interior de los mismos, moviliza a todos los ambientes científicos en la búsqueda de una cura o vacuna, disminuye algunas actividades que afectan el medioambiente, muestra la solidaridad de algunos países para ayudar a aquellos cuyos servicios sanitarios se encuentran superados en su capacidad, pero muestra también actitudes deshumanizantes en otros que se apropian de recursos médicos destinados a terceros, etc.. Las realidades que se avizoran en el futuro inmediato, se elaboran a partir de supuestos en algunos casos optimistas, mientras otros son apocalípticos. Es por todo eso que nos interesa aportar algunas reflexiones que nos acompañen en esta realidad, que se parece más a una virtualidad.

\section{Palabras Clave}

Educación - Medios - Pandemia 


\section{Summary}

The Pandemic established a new starting point, affecting the functioning of the world economy, preventing or hindering the movement of people between and within countries, mobilizing all scientific environments in the search for a cure or vaccine, decreasing some activities that affect the environment, shows the solidarity of some countries to help those whose health services are exceeded in their capacity, but also shows dehumanizing attitudes in others that appropriate medical resources for third parties, etc.. The realities that are drawn in the immediate future are drawn from assumptions in some cases optimistic, while others are apocalyptic. That is why we are interested in providing some reflections that accompany us in this reality, which is more like a virtuality.

\section{Key Words}

Education - Media - Pandemic.

El 28 de enero del año 2001, los movimientos sociales de muchos países del mundo firmaron en Porto Alegre (Brasil) un Compromiso al que denominaron "Otro Mundo es posible", con la intención de impulsar políticas que desmercantilicen las prácticas sociales, en la búsqueda de construir comunidades en las que la solidaridad sea el valor supremo y no la competencia de las economías de mercado. Esta declaración de los Movimientos Sociales tuvo influencia sobre partidos políticos progresistas y de izquierda, que impulsaron en sus programas, acciones orientadas en esa dirección.

El 11 de marzo de 2020, la Organización Mundial de la Salud, declaró la existencia de una Pandemia por la acción de un virus, el covid 19, sobre el que no existe, todavía, vacuna y/o remedios específicos. Como consecuencia de esta declaración, los países del mundo implementaron estrategias para contener la propagación y evitar el aumento de muertes, por esa causa. Las que dieron mejores resultados positivos fueron las que impusieron un aislamiento a las personas, impidiendo su movilidad salvo para realizar actividades determinadas y controlables.

Por esta razón, la mayoría de los países tuvieron que detener el funcionamiento de la producción, tanto en lo que respecta a la elaboración de mercancías, como al consumo de las mismas. Salvo rubros esenciales, la economía, tal como venía funcionando se detuvo. Esa economía, se 
caracterizaba por responder a una dinámica impuesta por las grandes corporaciones y los mega grupos financieros, que ejecutaban políticas de orientación neoliberal, favoreciendo la acumulación económica y profundizando las desigualdades sociales, con un exponencial crecimiento de la pobreza.

Cuando "el mundo se paró", comenzaron los análisis y especulaciones, en algunos casos, sobre cómo sería el mundo después de la pandemia. ¿Cómo sería la recuperación de la economía de todos los países?; ¿Quién o quienes los beneficiados o perjudicados?; ¿Es posible volver a los tiempos anteriores a esta situación?; ¿Cuáles serán los efectos del aislamiento sobre las poblaciones?; ¿Cómo sobrellevaron la cuarentena?; ¿Qué actividades pudieron desarrollar?; ¿Cuánto tiempo dedicaron a ver noticias o programas de televisión?; ¿A leer periódicos por internet?; etc.

Y aquí volvemos al principio: ¿Cuál es ese "Otro Mundo Posible", que comienza a perfilarse?, ¿Qué pasó durante este tiempo, en los que los niños/as, adolescentes y jóvenes no pudieron concurrir a las instituciones educativas?; ¿qué efecto tuvieron las estrategias diseñadas por docentes para tratar de no perder el contacto necesario implicado en una relación pedagógica?; ¿Cuánto tiempo le dedicaron a ese trabajo y cuanto al entretenimiento?; y ¿aquellos/as que no tenían la posibilidad de "conectarse a internet", cómo utilizaron su tiempo?, etc. ¿Qué influencia tuvieron los medios de comunicación? esto a nivel micro pero a nivel macro: ¿Cómo se recompone la economía?; ¿Quiénes van a conducir este proceso?; ¿Los mismos grupos económicos que ya estaban?; ¿Qué funciones recuperarán los Estados luego de tener que hacerse cargo de atender los infectados de la pandemia, y dedicar ingentes recursos para hacerlo?.

En Porto Alegre, los Movimientos Sociales, propusieron estrategias para cambiar la realidad social en aquellos países atravesados por situaciones de injusticia social. Desde ese momento y hasta la declaración de la Pandemia, varios países en los que se ejecutaron políticas sociales redistributivas y de contenido popular, fueron desplazados por "golpes blandos", "elecciones manipuladas", "traiciones a los programas ofrecidos en campaña", etc. (Ecuador, Colombia, Perú, Bolivia, Brasil, Argentina, Chile), todas acciones destinadas a restaurar políticas de orientación neoliberal.

La Pandemia estableció un nuevo punto de partida, ya que afecta el funcionamiento de la economía mundial, impide o dificulta la circulación de personas entre países y al interior de los 
mismos, moviliza a todos los ambientes científicos en la búsqueda de una cura o vacuna, disminuye algunas actividades que afectan el medioambiente, muestra la solidaridad de algunos países para ayudar a aquellos cuyos servicios sanitarios se encuentran superados en su capacidad, pero muestra también actitudes deshumanizantes en otros que se apropian de recursos médicos destinados a terceros, etc..

Este contexto, inédito en muchos sentidos, pone frente a un desafío a todas las sociedades y sus instituciones, ya que no es posible pensar un retorno a las "normalidades" anteriores. Las realidades que se avizoran en el futuro inmediato, se elaboran a partir de supuestos en algunos casos optimistas, mientras otros son apocalípticos.

Es por todo eso que nos interesa aportar algunas reflexiones que nos acompañen en esta realidad, que se parece más a una virtualidad.

\section{Medios de comunicación y educación: reflexiones detrás de los barbijos.}

En las últimas décadas, en los ámbitos académicos vinculados al estudio de las condiciones contextuales en las que se desarrollan los procesos educativos, hay un tema que ocupa un lugar importante en las preocupaciones de muchos/as docentes, investigadores/as y es el que se refiere a la necesidad de identificar el impacto de las nuevas tecnologías informáticas sobre las diferentes dimensiones involucradas con el hecho educativo. Simultáneamente, el desarrollo de las comunicaciones a través de diferentes plataformas tecnológicas, ha permitido nuevas formas de relacionamientos en la sociedad, influyendo sobre todas las actividades y modificando muchas de las prácticas. Las consecuencias, derivadas de estos dos procesos, se ponen de manifiesto en diferentes ámbitos, reformulando o poniendo en crisis, las actividades de algunas instituciones que, a lo largo del tiempo, habían cumplido con determinadas funciones para integrar las nuevas generaciones a la sociedad.

Los interrogantes que surgen de estos nuevos escenarios son muchos y las decisiones que deben realizar quienes tienen responsabilidad en el ámbito de la elaboración de políticas en educación, es posible agruparlas, en términos generales, en dos tendencias: quienes son optimistas sobre el papel de estas nuevas tecnologías sobre las distintas actividades humanas y los que con cierto pesimismo, consideran que sus efectos pueden llegar a ser negativos porque pueden afectar determinadas prácticas sociales existentes, generando desequilibrios que podrían crear nuevos conflictos en las sociedades. 
Por otra parte, los cambios sucedidos en el campo de las comunicaciones también pueden ser analizados en dos niveles. Por un lado, la posibilidad de la producción y distribución de mensajes ha roto con las limitaciones tecnológicas existentes en el pasado. La creación de escenarios virtuales, permite operar sobre los hechos reales, generando nuevas sensaciones a partir de lo que receptan nuestros sentidos. La "realidad" como construcción interpretativa de acontecimientos fácticos, se ve interpelada por la construcción de "realidades virtuales", que exponen una construcción intencionada para orientar las percepciones, el conocimiento y la comprensión de lo que sucede al interior de los procesos sociales. En segundo lugar, la "globalización" se manifiesta en el nivel de las comunicaciones, como una tendencia a la concentración de la propiedad y el dominio sobre los medios a través de los cuales se producen y difunden los relatos. El capitalismo en las actuales etapas de su desarrollo, necesita una base de consenso, que sólo se puede alcanzar si se logra la hegemonía de la concepción de mundo que subyace al modelo social neoliberal. Eso requiere de un triunfo cultural que permita establecer un "pensamiento único"i que favorezca la universalización de principios, valores, percepciones, etc. afines a la construcción de un orden mundial, controlado y dirigido por las grandes corporaciones, (principalmente financieras) que es la manera como el capitalismo se instituye como poder en esta etapa histórica.

En ese sentido Denis de Moraes sostiene que el sistema mediático," En primer lugar, evidencia capacidad de fijar sentidos e ideologías, formar opiniones y trazar líneas predominantes del imaginario social.ii Esta capacidad lo transforma en una herramienta estratégica para construir un sentido común que contribuya a la naturalización de las relaciones sociales existentes. El mismo autor sostiene que "Los proyectos mercadológicos y el énfasis editorial pueden variar, salvo en un punto clave: operan en consenso para reproducir el orden de consumo y conservar las hegemonías constituidas".iii

En un análisis convergente Manuel Castell ya alertaba que "(...) el poder depende del control de la comunicación, al igual que el contrapoder depende de romper dicho control". Y más adelante, señalaba: "mi hipótesis de trabajo es que la forma esencial de poder está en la capacidad para modelar la mente. La forma en que sentimos y pensamos determina nuestra manera de actuar, tanto individual como colectivamente. (...) La capacidad para lograr el consentimiento o al menos para instilar miedo y resignación respecto al orden existente es fundamental para imponer las reglas que gobiernan las instituciones y las organizaciones de la sociedad"iv. 
Estas consideraciones son muy importantes para poder evaluar la influencia que poseen hoy los medios de comunicación sobre los comportamientos sociales. Las nuevas tecnologías de las comunicaciones han producido un cambio en las funciones de los agentes que anteriormente cumplían esa tarea.

Para ello, creemos necesario recordar que en los procesos de conformación de los Estados Nacionales, las clases dominantes apelaron a la única herramienta que podía llegar a las mayorías o a los sectores sociales a quienes querían sumar como base de apoyo político. Los

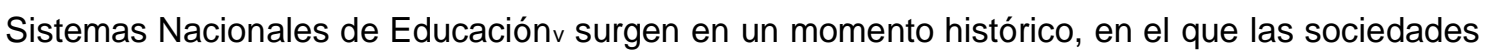
europeas estaban bajo la influencia de corrientes de pensamiento racionalistas en el campo de la Filosofía, partidarias de la universalización de determinados conocimientos con el fin de lograr las transformaciones materiales y de mentalidades requeridas por el nuevo orden social en construcción. En consecuencia las funciones que les fueron asignadas a esas instituciones no se limitaban a la adquisición de conocimientos y habilidades prácticas requeridas por el sistema productivo, sino que se buscaba generalizar comportamientos que favorecieran el desarrollo de una sociedad burguesa-capitalista. Paula Sibilia señala que "Al observarla bajo el prisma historiográfico, esa institución (escuela, colegio) gana los contornos de una tecnología (de época): se la puede pensar como un dispositivo, una herramienta o un intrincado artefacto destinado a producir algo."vi

Ese "algo", a la que estaba convocada la educación en estas primeras etapas de su historia formal, era la tarea de formar personas que pudieran adaptarse al contexto, incorporando aquellos conocimientos considerados "socialmente relevantes" y que en realidad eran expresión de las ideas de los grupos sociales dominantes, en el terreno de las prácticas políticas. Por medio de las instituciones educativas se proponía "naturalizar" ciertas prácticas sociales existentes, como así también reconocer un pasado histórico que ofreciera elementos para justificar ese presente. La "historia oficial" constituye un instrumento importante para construir una base de consenso social, ya que permite sostener continuidades y rupturas que sirven para legitimar un relato que distribuye virtudes y defectos, sacrificios y traiciones. La mentada "grieta" en la Argentina no es más que la continuidad de un conflicto social que comienza en la Independencia y atraviesa nuestra historia y que pone de manifiesto el enfrentamiento entre modelos sociales que defienden intereses antagónicos. 
Estas experiencias y vivencias de las sociedades a través del tiempo, contribuyen al proceso de integración social y las acciones involucradas aportan, de una manera u otra, a la formación de una mentalidadvii que otorga ciertas características a la sociedad. La mentalidad hegemónica se pone de manifiesto a través de prácticas y conceptualizaciones sobre lo cotidiano y muchas veces se traducen en generalizaciones sobre diferentes temas, sobre los que, en general, poseen una base empírica y no un fundamento elaborado, pero se sostienen como si no necesitaran contastación. Que se exalte la laboriosidad, inteligencia, creatividad, fortaleza, capacidad, velocidad, etc. a determinados grupos de la sociedad o de otras sociedades, es la manera como, algunos/as, perciben a los/as otros/as, aceptando, de forma inconsciente, una opinión sobre sí mismos y sus posibilidades.

El estudio de estos temas constituye un aporte importante a las investigaciones en el terreno de la educación y las comunicaciones ya que ofrece elementos distintos para interpretar ciertos comportamientos colectivos que no se corresponden con algunas categorías de análisis. Un ejemplo es la transversalidad de adherentes en algunos de los bordes de la "grieta", recuperando como fundamentos de sus opiniones relatos elaborados desde maneras de interpretar la realidad, por parte de quienes legitiman las desigualdades sociales.

La educación, a través de sus prácticas y contenidos, fue una herramienta importante durante los últimos dos siglos, para formar la mentalidad de las nuevas generaciones inculcando las actitudes requeridas por el modelo social dominante. Las críticas y cuestionamientos a esta función provino de matrices teóricas críticas que cuestionaban las bases del sistema económico, social y político capitalista, y que sirvió para dejar en evidencia el contenido político de la educación en todos sus niveles.

En los procesos de adaptación social hay temas que son necesarios para establecer y mantener el orden social. Por esa razón la educación fue un área estratégica de disputa política. ¿Enseñar religión en las escuelas públicas?; ¿Establecer obligatoriedad en todos los niveles?; ¿Permitir la educación privada en los estudios superiores?; ¿Qué contenidos deben ser prioritarios?;¿Cuánto tiempo dedicar a las materias "culturales"; ¿Debe la escuela impartir educación sexual?; ¿Cuáles son los valores que se deben promover en los niveles básicos?; etc.. La manera como se resolvieron estas disputas permite evaluar las correlaciones de fuerza entre sectores sociales y políticos y las consecuencias para el devenir del sistema educativo. 
Los diferentes proyectos educativos, pusieron énfasis en aspectos que se consideraban prioritarios en función del modelo social. Durante algunos gobiernos, se dio impulso a la formación relacionada con el desarrollo industrial, fue el caso de J.D.Perón durante su primer gobierno, continuada luego con altibajos durante los gobiernos desarrollistas y rescatada nuevamente en el gobierno de Nestor Kirchner. Los gobiernos impuestos por los golpes cívicomilitares, siempre se proclamaban restauradores del orden social y sus acciones políticas, que respondían a intereses de tradicionales grupos sociales, eran ocultados apelando a una retórica centrada en valores morales propios de la religión católica. Las políticas educativas elaboradas por estos grupos civiles y militares, tendían a fortalecer principios de autoridad para favorecer actitudes de aceptación de la existencia de "jerarquías naturales". Esto seguramente estaba en el pensamiento del Dr. Raúl Alfonsín cuando nos dio a entender que "todos llevamos un enano autoritario en nuestra mochila".

La educación pública argentina fue receptora de los avatares políticos, siendo afectada en los gobiernos que no la consideraban fundamental y defendida en aquellos que le asignaban una función necesaria para superar los atrasos en el desarrollo científico-tecnológico-social. En forma paralela, la educación privada cumplió con dos funciones requeridas por el sistema económicosocial: incorporar principios y valores propios de una sociedad meritocrática, y en algunas más destacadas, favorecer la formación de una clase empresarial y política que pretendía erigirse en una elite llamada a ser dirigente. El logro cultural de estas instituciones consiste en establecer una diferenciación social entre "los unos y los otros" reforzando la justificación de las desigualdades sociales, y aportando a la formación de un "sentido común" individualista y competitivo.

La educación en las instituciones a las que asisten "las clases altas argentinas", se basa en valores tradicionales y el objetivo, en algunas de ellas, no es acceder a una formación superlativa, en términos académicos, sino a la búsqueda de relacionarse con quienes se consideran pares. Un valioso estudio sobre este tema destaca que "La distinción pasa por la posibilidad de acceder al "club de los elegidos": el primer signo de pertenecer es el colegio al que vas. Ante el acceso igualitario a la escuela común y la masificación del sistema educativo, la clase alta se abroquela en algunas instituciones que dan el acceso a redes y a valiosas relaciones cara a cara". viii Un ejemplo cercano en el tiempo lo representa el gobierno de Mauricio Macri, quien se rodeó en la gestión, de excompañeros del "Cardenal Newman". 
Todas estas situaciones contribuyeron a la fragmentación del sistema educativo, en el que se fortalecieron algunas tendencias conservadoras en términos sociales y políticos. Un ejemplo de ello es el hecho de que todavía se debate (en Salta principalmente) si la enseñanza de la religión debe ser obligatoria en las escuelas públicas o si se debe enseñar Educación Sexual Integral en ellas.

En las últimas décadas y como consecuencia de situaciones políticas que enfrentaron estrategias contradictorias como resultado de sus opciones sociales, la educación formal se ha visto afectada en su función de educar para el futuro, manteniendo en muchos casos, su legado como herramienta para la reproducción del sistema social.

Desde mediados del siglo XX, las instituciones educativas se enfrentan a una nueva realidad que está dada por el vertiginoso desarrollo de las tecnologías informáticas y de las comunicaciones. Los nuevos soportes tecnológicos, modifican la manera como las nuevas generaciones, se relacionan entre ellas y con el mundo. Esto influye de múltiples maneras sobre las prácticas sociales y el acceso a estas plataformas modifica la relación espacio-tiempo, realidad-virtualidad, información-conocimiento, condiciones que de alguna manera entran en competencia, desigual, con las instituciones educativas, que en muchos casos mantienen formas y contenidos que las hacen menos atractivas.

Las nuevas tecnologías informáticas y de las comunicaciones constituyen un elemento fundamental para influir sobre la manera de actuar en el nuevo mundo, estableciendo una competencia con las instituciones educativas, que realizaban esa tarea.

Si bien es conocido que los medios de comunicación han cumplido una función estratégica para el fortalecimiento y expansión del capitalismo, los actuales cambios tecnológicos han potenciado su poder incidiendo sobre todos los sistemas políticos.

En las últimas décadas el "poder de los medios" adquirió una nueva dimensión y los/as estudiosos/as sobre su función política, destacan que la antigua consideración de la prensa como "cuarto poder" se ha modificado, y en algunos procesos políticos de los últimos años, el grado de influencia sobre la opinión de los ciudadanos/as, ha permitido imponer determinadas figuras en la política, que no responden a los modelos clásicos. El paso del mundo del espectáculo a la actividad política es consecuencia de la influencia que ejercen los medios y los equipos de asesores tienden a ser reclutados en agencias de marketing, antes que en ámbitos especializados en los temas que requiere esa actividad. El grado de influencia sobre la "opinión 
pública", ha permitido que "noticias falsas" sean consideradas "verdaderas", aun en el caso que se demuestre su falsedad.

En las actuales condiciones, la educación y los medios de comunicación ocupan un lugar central en la formación del sentido común que se requiere para la estabilidad de un programa político. Los sistemas educativos, como hemos mencionado, cumplieron varias funciones durante el siglo XX. Unas ligadas al modelo de desarrollo económico y otras a la reproducción de una cultura que permitiera la continuidad del sistema. En las distintas etapas de la historia argentina es posible observar el interés de las fuerzas políticas por hacer cumplir estos mandatos. Se pueden destacar algunos ejemplos. Con posterioridad al derrocamiento de Hipólito Yrigoyen en 1930, se produjo, a nivel de los contenidos educativos, lo que se conoce como la "reacción espiritualista" o "antipositivismo", políticas impulsadas desde el gobierno, respondiendo a los requerimientos de la Iglesia Católica. En el primer gobierno de Juan D. Perón se crearon las Escuelas Fábricas y la Universidad Obrera, ambas relacionadas con el modelo industrialista y se estableció la enseñanza religiosa en las escuelas. En el breve gobierno de Héctor J. Cámpora se incorpora a la currícula del nivel medio, la asignatura Estudio de la Realidad Argentina (ERSA), que estaba destinada a incorporar conocimientos del área social, desde una perspectiva crítica, y que fue anulada en la Dictadura, reemplazándola por Formación Moral y Cívica. En este llamado "Proceso de Reorganización Nacional", se impuso lo que se conoce como Orden Expresivo y Orden instrumental. Uno destinado a erradicar todos los contenidos que se consideraban "subversivos" y otro orientado a disciplinar las instituciones y a los/as docentes.

$\mathrm{Si}$ hacemos un estudio comparativo con lo que también sucedía en los medios, es posible observar cómo la prensa, luego la radio y finalmente la televisión, fueron ocupando un espacio importante en la sociedad, como formadoras de opinión y fuente de noticias. A partir de la década del '70 las transformaciones tecnológicas adquieren mayor intensidad y su influencia sobre la cultura, en general, fue creciente. La televisión introduce, a través de diferentes formatos, las actitudes, comportamientos, gustos, etc. portadores de una carga valorativa que generaba expectativas de consumo y destinadas a los diferentes grupos sociales. La formación de las "mentalidades", comienza a ser asumida por estos medios y comienza la competencia, cada vez más desigual con la educación. El clásico libro de Ariel Dorfman y Ardmand Mattelart "Para leer el Pato Donald" (1972), es un ejemplo de la preocupación de muchos intelectuales de las comunicaciones, por mostrar el poder de los medios, como promotores de actitudes de 
aceptación y adaptación al sistema social. La llegada y creciente generalización de la informática, contribuye a la creación de nuevos instrumentos tecnológicos, utilizados para realizar actividades que incluyen, comunicaciones interpersonales, acceso a conocimientos de temas de todas las ciencias, elaboración de producciones en formato digital, etc., destinadas principalmente al consumo de las generaciones más jóvenes.

Todas estas nuevas realidades entran en colisión con algunas de las funciones que venía desempeñando la educación. Se genera un intercambio de relatos, en muchos casos contradictorios, por estar llamadas a cumplir funciones diferentes en la sociedad. Si bien la educación tiene como una de sus premisas la formación de las nuevas generaciones para incorporarse a una forma de vida dentro del sistema social, los mensajes de los medios se dirigen a uno de sus aspectos, que es el de ser "consumidor/a" ya que, tanto las empresas propietarias, como quienes contribuyen a su sostenimiento, son parte de la estructura económica del sistema capitalista.

Para algunos estudiosos del tema, el poder que desarrollaron los medios de comunicación, es una consecuencia de que "vivimos en un mundo repleto de imágenes y palabras. $Y$ esas imágenes y esas palabras no llegan desde otro planeta: conforman, constituyen, diseñan, construyen y rearman el universo que habitamos. En ese marco, los medios son uno de los actores con mayor peso para hacer circular imágenes y palabras para disputar los sentidos sociales del mundo compartido."ix. La posibilidad de crear y difundir relatos sobre todos los acontecimientos sociales permite la inculcación de cosmovisiones que influyen en la manera como se percibe la realidad y define algunos de los comportamientos que se ejecutan en la práctica. El dominio de algunas de estas herramientas tecnológicas, facilita un mayor control social, por parte de los grupos sociales dominantes. En ese sentido la TV y las tecnologías informáticas de las comunicaciones, han demostrado ser muy eficaces para influenciar las conductas de diferentes sectores de la sociedad, lo que las ha transformado en un eficaz instrumento de poder político y control social.

En esta encrucijada, uno de los temas que preocupan a los /as investigadores en el ámbito educativo, es en qué grado la educación sigue ocupando un lugar importante para la formación de las nuevas generaciones o si ese lugar lo ocupa de forma creciente, los instrumentos informáticos y los medios de comunicación. 
La importancia política de este tema radica en el hecho de que los medios y las plataformas digitales son, en términos globales, dominados por quienes poseen un poder económico, científico y tecnológico que les permite someter a sus intereses a la mayoría de los EstadosNación, que integran esta "globalización neoliberal" impuesta por esos mismos factores de poder. Las instituciones del sistema educativo siguen teniendo importancia, ya que la relación pedagógica no se limita a la "transmisión de conocimientos y formación de actitudes". Sin embargo las nuevas tecnologías ocupan, de forma creciente, un lugar central en la vida de la mayoría de quienes asisten en los distintos niveles del sistema, modificando aspectos de la cultura heredada.

El interés por incorporar estos elementos al trabajo docente es una tarea que tiene algunos antecedentes en el pasado (radio y tv escolar) pero que requiere un conocimiento más especializado para poder utilizarlos. Una limitación que surge está vinculada a las condiciones económicas existentes, ya que las posibilidades de acceso y conectividad reproduce las desigualdades sociales.

En los actuales momentos, que vive el mundo y la Argentina, por la presencia de un virus de reproducción masiva y de mucha gravedad, se produjo una situación desconocida para la mayoría de la población y que obligó a reformular comportamientos cotidianos. La cuarentena o aislamiento preventivo, reestructuró nuestra percepción del espacio-tiempo, afectando todas las relaciones sociales.

En una recordada viñeta de Mafalda, ella pedía que el mundo se detuviera para poder bajar. Algo parecido sucedió en esta coyuntura, aunque la posibilidad de bajarse del mundo no fue posible, dada la necesidad de recluirse en el lugar de residencia.

En esa condición de aislamiento se presentan dos situaciones que involucran a la educación, por una parte y a los medios de comunicación, por otra.

En el desarrollo de este trabajo, hemos tratado de presentar el papel que tuvo y tiene la educación en los procesos de adaptación a la sociedad, incorporando pautas de comportamiento, requeridas por el sistema económico-social. Sin embargo, en los últimos años muchas de las investigaciones han mostrado la existencia de un deterioro en la formación de quienes asisten a las instituciones educativas, principalmente en el nivel medio y superior. La fragmentación del sistema y la desarticulación entre los niveles, se agrava con la utilización de las nuevas tecnologías informáticas. Algunos/as acceden y se familiarizan con ellas, mientras que otros/as 
no las poseen. De manera creciente, los medios de comunicación y las nuevas formas de producción, intercambio y relacionamiento comunicacional, que poseen las nuevas generaciones, interpelan a las formas clásicas de relacionamiento, contribuyendo al surgimiento de una sociedad diferente a la de las generaciones mayores. Este es el contexto actual, el ámbito donde se presenta el covid-19.

En la situación impuesta por la pandemia, las clases se vieron suspendidas y ante la posibilidad de que se prolongara el aislamiento, se solicitó a los docentes de los distintos niveles, la elaboración de actividades que pudieran mantener la relación educativa.

En la mayoría de los casos las clases virtuales tuvieron que realizarse con los medios disponibles tanto por parte de los docentes como de los/as estudiantes. Estas condiciones de trabajo generaron situaciones que fueron destacadas por asociaciones profesionales y gremios. En algunos casos, principalmente en los primeros grados de la escuela primaria, las/os maestros/as manifestaban sentirse expuestos ante la familia, que intervenía directa o indirectamente, explícita o implícitamente, en las actividades propuestas. Se mencionaba además, que en el trabajo en el aula, hay una relación de "complicidad" entre educador y educandos, que no puede realizarse a través de los medios electrónicos. En los niveles medio y superior, los problemas se vinculan de manera más clara con las posibilidades económicas, que se manifiestan en el acceso a computadoras o celulares con capacidad de memoria para utilizarlos en las tareas.

Un hecho destacable es que, por la fecha en que se estableció la suspensión de clases (16-03) muchos docentes no llegaron a conocer el grupo de estudiantes, situación que agrega un obstáculo muy importante ya que tampoco los estudiantes conocen al docente y en muchos casos son materias nuevas, de complejidad variada.

La lista de problemas que se presentan es muy extensa, ya que existen situaciones relacionadas al contexto social, la ubicación geográfica de las instituciones, la cobertura y capacitación docente para operar con las nuevas tecnologías, etc.. Por la manera como se presentó el problema, una situación de la que se poseen elementos fragmentarios, tiene que ver con la manera como vivieron y percibieron estas nuevas generaciones a las que hicimos referencia, frente a una situación poco común y que seguramente incidió sobre la forma de vinculación con su entorno,anterior a la pandemia.

La educación post-pandemia va a enfrentar a una realidad económica, social y política muy diferente a la que existía antes del virus y eso seguramente deberá ser objeto de estudios, 
debates y elaboración de nuevas estrategias de acción. La crisis que atravesaba la educación pública, como consecuencia de situaciones históricas agravadas en los últimos años, agrega a sus diagnósticos nuevos elementos que complejizan el panorama. Sin embargo, también hay posibilidades que estas situaciones rompan con cierta inercia en el funcionamiento de las instituciones y movilicen las expectativas docentes, orientando su formación para responder a las exigencias del momento histórico presente. Esto no implica solamente la apropiación de saberes técnicos para operar con las nuevas tecnologías, sino que la capacitación debe incluir, lo que ha quedado al descubierto de la forma como está organizado y funcionando el mundo. Este virus permitió que se realice una especie de radiografía, en la que es posible ver, detrás de las apariencias, las grandes diferencias sociales entre ricos (muy pocos) y pobres (mayoría); la destrucción del medio ambiente y sus consecuencias sobre los seres humanos; la necesidad de que existan Estados que provean los bienes necesarios para un buen vivir; la importancia de recuperar el control sobre las empresas que proveen los servicios fundamentales para poder tener una vida digna; la importancia de sostener institutos de investigación que brinden a la comunidad los avances de la ciencia en todas sus aplicaciones, la necesidad de un mayor compromiso ciudadano basado en la solidaridad, etc.

Quizás también ha quedado en evidencia la importancia creciente de las comunicaciones y la necesidad de poder utilizarlas para mejorar las relaciones sociales evitando dejar librado "al mercado", su potencialidad. En la primera parte hemos presentado algunos de los análisis que muestran la importancia política que han adquirido los medios.

En los últimos años, la sociedad argentina ha sido objeto de múltiples operaciones políticas, utilizando los medios de comunicación para profundizar históricas divisiones en la sociedad. La tendencia a la concentración de la propiedad y control de los contenidos que difunden los medios, forma parte de una estrategia a nivel mundial, para conformar mentalidades receptoras de valores y principios que permitan la reproducción del sistema económico-social.

Ese poder, que en la Argentina lo representa el conglomerado Clarín y en menor medida, aunque con influencia en ciertos grupos sociales, La Nación, operó activamente para impedir y/o combatir políticas redistributivas y de control del capital, llevadas a cabo por algunos gobiernos populares. Algunas investigaciones han puesto en evidencia estas acciones y la forma como se relacionaban con sectores de la Justicia y algunos grupos políticos. 
Uno de los interrogantes que motivó nuestras reflexiones, forma parte de un interés por estudiar de que manera las herramientas informáticas y de las comunicaciones, se enfrentan con algunas funciones que la educación formal, desempeñó en los dos últimos siglos. El aislamiento que impuso la pandemia, seguramente ha de ofrecer datos e informaciones que permitan analizar algunas hipótesis que nos formulamos. El tema es complejo, ya que en el intervienen muchas variables, y las consecuencias, seguramente, se pondrán de manifiesto en las prácticas políticas y sociales. La incidencia del mensaje de los medios sobre distintos temas de interés, la manera como se reorganizaron los tiempos en cada contexto familiar, la importancia y dedicación que se dio a las estrategias de formación enviadas desde las escuelas, colegios, universidades, el tiempo dedicado a programas de entretenimiento, noticiosos, de polémica política, etc. nos permitirá comprender algo más de las mentalidades que portamos como sociedad.

El futuro, más que antes, es muy incierto. Existe consenso en muchos estudios y análisis, que el mundo que sucederá a esta situación crítica, no será igual al que existía, aunque no existe unanimidad en las proyecciones. ¿Fortalecimiento de las actuales políticas mundiales?; ¿Recuperación de principios solidarios en las políticas públicas?; ¿Derrumbe de los centros de poder financiero mundial?; ¿Establecimiento de un nuevo orden mundial en el que los EE.UU. no tengan hegemonía absoluta?; ¿Corrimiento hacia la derecha política, en la mayoría de las potencias, profundizando acciones de segregación racial, social y cultural?; ¿Establecimiento de una Renta Básica Universal, que contribuya a mejorar las condiciones de vida de los/as trabajadores/as?; son algunas de las líneas de acción que se encuentran en debate.

Hemos utilizado al inicio, la consigna de los movimientos sociales de que "Otro mundo es posible", convocatoria que se presentó para enfrentar las políticas neoliberales aplicadas en casi todos los países desde la década de los ' 80 y que profundizaron las desigualdades sociales, aumentando pobreza, indigencia y marginalidad.

Hemos tratado de mostrar cómo esta pandemia, montó un laboratorio para realizar diferentes estudios sobre los comportamientos sociales en situaciones críticas. Hemos reafirmado la convicción del creciente poder de los nuevos y viejos sistemas de comunicación y los que provienen de los desarrollos informáticos.

Hemos tratado de dejar algunas pistas sobre hacia donde se dirige nuestra búsqueda. Estamos en los primeros tramos del camino.

Pero, tenemos la esperanza de que es muy importante pensar que "Otro mundo es posible". 


\title{
Notas:
}

\begin{abstract}
¡ Ramonet, Ignacio 1997 Géopolitique du chaos (París: Galilée).
ii De Moraes y Otros (2013) "Medios, Poder y Contrapoder”. Ed.Biblos. Bs.As. iii Idem. Pág 23.

iv Castell, M. (2012) "Comunicación y Poder". Pág 24.Ed. Siglo XXI. Mejico.

$\checkmark$ "Por sistema educativo nacional entendemos una red o conjunto de instituciones de educación formal diferenciadas y relacionadas entre sí, gestionadas y/o controladas por agentes públicos, costeadas por el erario público y a cargo de profesores nombrados y supervisados por dichos agentes y retribuidos con cargo a un presupuesto asimismo público". Antonio Viñao. Citado por Barreiro, H. (2005) "La institución escolar una creación del estado moderno" .Ed. Octaedro. Barcelona. España.

vi Sibilia, P. (2012) ¿Redes o Paredes?. La escuela en tiempos de dispersión. Ed. Tinta Fresca. Bs. As.

vii Las mentalidades constituyen,según José Luis Romero, una característica que permite reconocer las particularidades que definen al modelo social vigente. Según sus palabras "En cualquier sociedad (...) hay ciertas ideas de las que, po una especie de consenso tácito, no se admite la posibilidad que sean sometidas a juicio. Junto a ellas hay algunas menos arraigadas y otras que finalmente son ocasionales, son ideas de una época, de un tiempo, de un período y que conjuntamente conforman una red muy complicada. Y agrega " (...) la mentalidad de un grupo es algo que se objetiva pero que al mismo tiempo vuelve, o para decirlo más exactamente primero se vive y luego puede ser objetivado. Constituye un sistema de ideas operativas, de ideas que mandan, que resuelven, que inspiran reacciones. Son también ideas valorativas y normativas condicionantes de los juicios de valor sobre las conductas.

viii Gessaghi, V. (2016) "La educación de la clase alta argentina". Pág. 251. Siglo XXI. Bs.As.

ix Schuliaquer, I. (2014) “El poder de los medios" Pág. 10. Ed. Capital Intelectual. Bs. As.
\end{abstract}

